ARTICLE

Received 2 Jan 2014 | Accepted 6 Jun 2014 | Published 7 Jul 2014

DOI: $10.1038 /$ ncomms5327 OPEN

\title{
Facile synthesis of pentacle gold-copper alloy nanocrystals and their plasmonic and catalytic properties
}

Rong He $\mathrm{He}^{1,2}$, You-Cheng Wang ${ }^{1}$, Xiaoyong Wang ${ }^{3}$, Zhantong Wang ${ }^{3}$, Gang Liu ${ }^{3}$, Wei Zhou ${ }^{1}$, Longping Wen?', Qunxiang $\mathrm{Li}^{1,2}$, Xiaoping Wang ${ }^{1,4}$, Xiaoyuan Chen ${ }^{5}$, Jie Zeng ${ }^{1,2}$ \& J.G. Hou ${ }^{1,4}$

The combination of gold and copper is a good way to pull down the cost of gold and ameliorate the instability of copper. Through shape control, the synergy of these two metals can be better exploited. Here, we report an aqueous phase route to the synthesis of pentacle gold-copper alloy nanocrystals with fivefold twinning, the size of which can be tuned in the range from 45 to $200 \mathrm{~nm}$. The growth is found to start from a decahedral core, followed by protrusion of branches along twinning planes. Pentacle products display strong localized surface plasmon resonance peaks in the near-infrared region. Under irradiation by an 808-nm laser, 70-nm pentacle nanocrystals exhibit a notable photothermal effect to kill 4T1 murine breast tumours established on BALB/c mice. In addition, 70-nm pentacle nanocrystals show better catalytic activity than conventional citrate-coated 5-nm Au nanoparticles towards the reduction of $p$-nitrophenol to $p$-aminophenol by sodium borohydride.

\footnotetext{
${ }^{1}$ Hefei National Laboratory for Physical Sciences at the Microscale and Collaborative Innovation Center of Suzhou Nano Science and Technology, University of Science and Technology of China, Hefei, Anhui 230026, P.R. China. ${ }^{2}$ Center of Advanced Nanocatalysis (CAN-USTC) and Department of Chemical Physics, University of Science and Technology of China, Hefei, Anhui 230026, P.R. China. ${ }^{3}$ State Key Laboratory of Molecular Vaccinology and Molecular Diagnostics \& Center for Molecular Imaging and Translational Medicine, School of Public Health, Xiamen University, Xiamen, Fujian 361102, P.R. China. ${ }^{4}$ Synergetic Innovation Center of Quantum Information and Quantum Physics, University of Science and Technology of China, Hefei, Anhui 230026, P.R. China. ${ }^{5}$ Laboratory of Molecular Imaging and Nanomedicine (LOMIN), National Institute of Biomedical Imaging and Bioengineering (NIBIB), National Institutes of Health, Bethesda, Maryland 20892, USA. Correspondence and requests for materials should be addressed to J.Z. (email: zengj@ustc.edu.cn).
} 
T hrough mixing two or more species, the scope of properties of metal nanocrystals can be significantly extended owing to various synergistic effects ${ }^{1-10}$. For example, forming hybrid, core-shell or alloy structures leads to affluent and interesting chemical and physical characteristics especially in catalysis and optics for both fundamental study and niche applications ${ }^{11-19}$. As a particular species of great service, gold nanocrystals exhibit unique and often tunable properties such as localized surface plasmon resonance (LSPR), biocompatibility, easy surface modification and catalytic effect towards many important oxidization reactions, which promote their comprehensive applications such as photothermal therapy, cancer diagnosis, imaging, drug delivery and pollution control $^{20,21}$. As another coinage metal, copper share many welldefined shapes discovered for Au when forming nanocrystals ${ }^{22-27}$. Analogous to $\mathrm{Au}$ and other noble metals, $\mathrm{Cu}$ nanocrystals can display strong LSPR absorption in the spectral range of visible and near-infrared (NIR) ${ }^{26,27}$. However, the susceptibility of $\mathrm{Cu}$ upon exposure to air complicates the synthesis and applications of $\mathrm{Cu}$ nanocrystals. Therefore, the combination of $\mathrm{Au}$ and $\mathrm{Cu}$ will predictably pull down the high cost of $\mathrm{Au}$ and ameliorate the instability of $\mathrm{Cu}$ towards oxidization. There have been a few reports in literature on the synthesis of well-defined $\mathrm{Au}-\mathrm{Cu}$ bimetallic nanocrystals ${ }^{28-30}$. Liu and Walker achieved the production of $\mathrm{Au}-\mathrm{Cu}$ alloy nanocubes through a one-pot polyol strategy ${ }^{28}$. They found that the LSPR wavelength of nanocubes was highly dependent on size and composition. Chen et al. reported a protocol employing the diffusion of newly reduced active $\mathrm{Cu}$ atoms into pre-synthesized $\mathrm{Au}$ seeds to prepare intermetallic $\mathrm{Au}-\mathrm{Cu}$ nanocrystals ${ }^{29}$. Distinct from solid-state diffusion, the solution phase, atomic-scale diffusion is homogeneous and generates uniform and monodisperse products. Apart from using chemical methods, Yin et al. ${ }^{30}$ reported the preparation of mass-selected $\mathrm{Au}-\mathrm{Cu}$ core-shell clusters containing several thousand atoms through a magnetron-sputtering gas phase method. By manipulating the condensation parameters, size, composition and structure of the bimetallic nanocrystals can be controlled.

Despite these remarkable demonstrations, $\mathrm{Au}-\mathrm{Cu}$ bimetallic nanocrystals that have been reported are limited in well-defined shape and are mostly enclosed by low-index facets including $\{111\},\{100\}$ and $\{110\}$. Since controlling the crystalline structure and exposed facets of metal nanocrystals have always provided a powerful means to modulate their properties, there is a unremitting drive to pursue diverse interesting shapes, for instance, nanocrystals with multiple branches. In general, highly branched nanocrystals enjoy higher surface-to-volume ratio and possibly rougher surfaces than their more isotropic counterparts, both of which can avail surface-sensitive applications such as LSPR and catalysis ${ }^{31-33}$. In addition, it has been pointed out that nanostructures with branched arms on the surface are often endowed with high-index feature ${ }^{34-37}$. High-index facets relate to a high density of atomic steps, kinks and edges with low coordination numbers, which can act as highly active sites for breaking chemical bonds ${ }^{33-37}$. Since limited success has been accomplished in the synthesis of bimetallic nanocrystals with multiple branches, it is of significant value to investigate the synergy between $\mathrm{Au}, \mathrm{Cu}$ and branched shape, which can probably uphold the application of $\mathrm{Au}-\mathrm{Cu}$ bimetallic nanocrystals.

Herein we present a facile approach to size-controlled synthesis of pentacle $\mathrm{Au}-\mathrm{Cu}$ alloy nanocrystals with fivefold twinning in aqueous solution. By adjusting the amount of capping agent, we also obtain nanocrystals in other shapes including polyhedrons and nanorod networks. The as-prepared pentacle nanocrystals can display strong LSPR peaks in the NIR region, which makes them possible potent agents for photothermal therapy.
Upon irradiation by a NIR laser $\left(808 \mathrm{~nm}, 1 \mathrm{~W} \mathrm{~cm}^{-2}\right)$, the $70-\mathrm{nm}$ pentacle nanocrystals exhibit a notable photothermal effect to kill 4T1 murine breast tumour cells. It is further discovered from photothermal treatment in vivo that $70-\mathrm{nm}$ pentacle nanocrystals are able to regress the tumours on $4 \mathrm{~T} 1$ tumour-bearing $\mathrm{BALB} / \mathrm{c}$ mice. In addition, the pentacle $\mathrm{Au}-\mathrm{Cu}$ alloy nanocrystals show better catalytic activity than polyhedrons and nanorod networks that are mostly enclosed by low-index facets towards the reduction of $p$-nitrophenol into $p$-aminophenol by sodium borohydride $\left(\mathrm{NaBH}_{4}\right)$. With sizes down to 70 and $45 \mathrm{~nm}$, pentacle products appear to be even more active than conventional 5-nm Au nanoparticles. Our results show that pentacle $\mathrm{Au}-\mathrm{Cu}$ alloy nanocrystals can be used as a versatile and diverse platform in biomedical applications owing to their tunable plasmonic properties, and that they have great potential as industrial catalysts.

\section{Results}

Structure and composition study. The standard aqueous phase synthesis of pentacle $\mathrm{Au}-\mathrm{Cu}$ alloy nanocrystals involves $\mathrm{CuCl}_{2}$ and $\mathrm{HAuCl}_{4}$ as precursors, glucose as the reductant and hexadecylamine (HDA) as the capping agent. At first, aqueous solutions of $\mathrm{CuCl}_{2}, \mathrm{HAuCl}_{4}$ and glucose were added into a glass vial containing a mixture of HDA and deionized water. After being capped, the vial holding the final solution was magnetically stirred at room temperature overnight. It was then transferred into an oil bath and heated at $100^{\circ} \mathrm{C}$ for $30 \mathrm{~min}$. As the reaction proceeded, the solution changed its colour from kelly green to deep brown. Figure 1a shows a representative scanning electron microscopy (SEM) image of a sample prepared through the standard procedure, which indicates the purity and uniformity of the products. The nanocrystals consisted of five branches, which were $10-40 \mathrm{~nm}$ in width and $80-150 \mathrm{~nm}$ in length, with an angle of $\sim 72^{\circ}$ between adjacent ones. The inset, a magnified image to show a single particle, confirms the fivefold symmetric structure. To better substantiate, extra transmission electron microscopy (TEM) and SEM images of different individual pentacle nanocrystals are provided in Supplementary Fig. 1. To visualize the crystalline structure of the as-prepared pentacle $\mathrm{Au}-\mathrm{Cu}$ alloy nanocrystals, TEM and high-resolution TEM (HRTEM) analysis were conducted. Figure $\mathrm{lb}$ shows a typical pentacle $\mathrm{Au}-\mathrm{Cu}$ alloy nanocrystal on which HRTEM measurements were performed. Figure 1c,d shows HRTEM images recorded along the [110] zone axis, of the regions marked by boxes in Fig. 1b. In both images, periodic lattice fringes can be clearly seen. The lattice spacings marked around the core area (Fig. 1c) and branch ends (Fig. 1d) can all be indexed to $\{111\}$ planes. As shown in Fig. 1d, the $\{111\}$ twinning planes extended along to the end of the branch. Additional HRTEM images taken from different parts are integrated in Supplementary Fig. 2 to support an almost fivefold symmetric structure. Notably, the terraces on the edge marked with black lines in Fig. 1d probably correspond to high-index facets. Figure 1e shows the selected-area electron diffraction pattern obtained with the electron beam aligned parallel to the fivefold axis, that is, the [110] directions. It furnishes compelling evidence for the fivefold symmetric crystalline structure of the pentacle nanocrystals. The circles correspond to electron diffractions from the $\{111\}$ planes while the boxes correspond to those from the $\{200\}$ planes $^{38}$. Figure $1 \mathrm{f}$ is a scanning TEM (STEM) image of a typical pentacle nanocrystal, on which elemental mapping analysis was induced. Figure 1g,h shows STEM-energy dispersive $\mathrm{X}$-ray (STEM-EDX) elemental mapping of $\mathrm{Cu}$ and $\mathrm{Au}$, respectively. The full coverage of both $\mathrm{Cu}$ and $\mathrm{Au}$ reveals the alloy structure. The merged image (Fig. 1i) further approves the complete overlapping of two metal components. The composition 


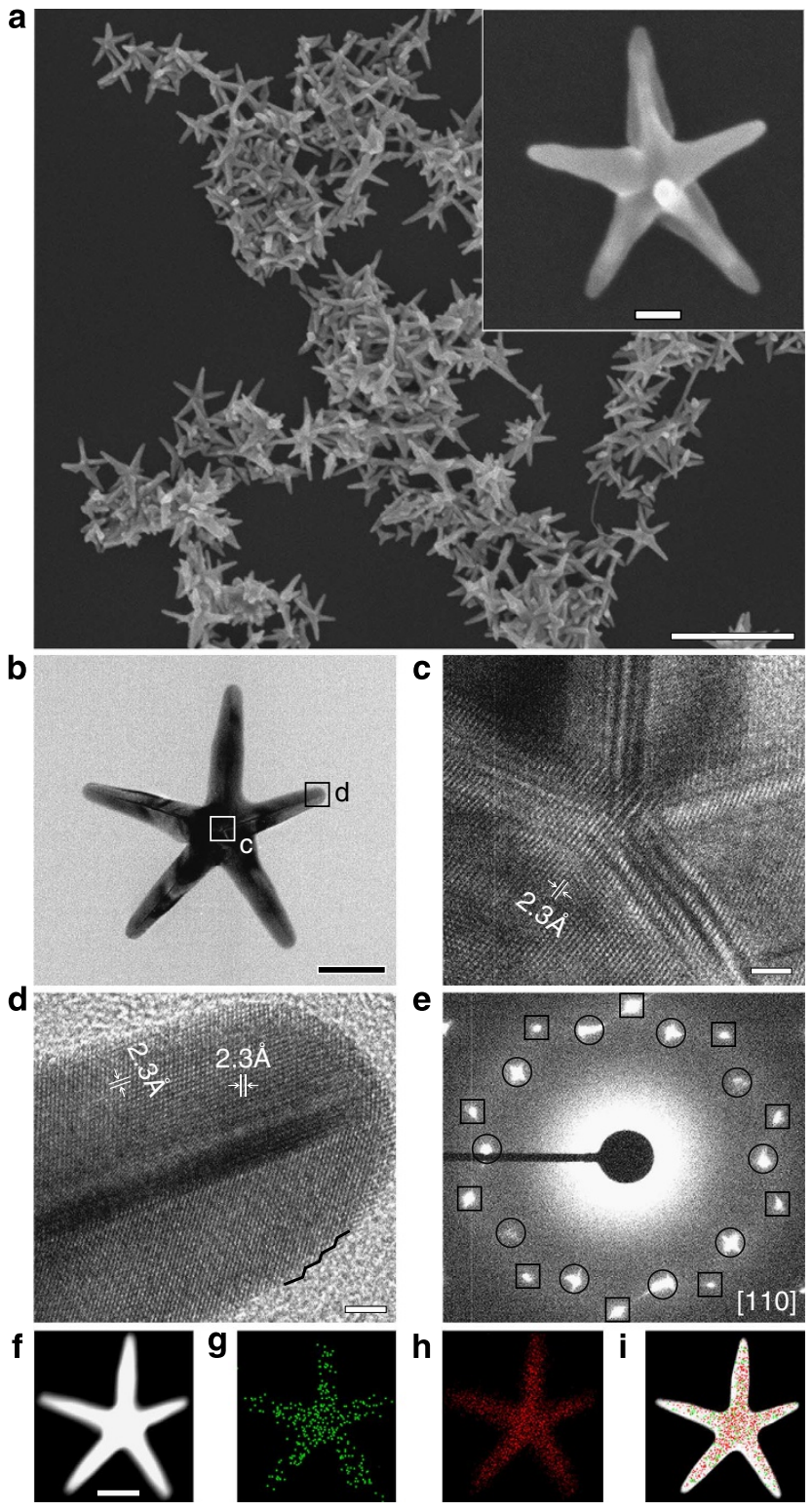

Figure 1 | Structure and composition study of pentacle $\mathrm{Au}-\mathrm{Cu}$ alloy nanocrystals. (a) SEM image of the pentacle nanocrystals prepared through the standard procedure. The inset shows a SEM image of a typical individual nanocrystal. (b) TEM image of an individual pentacle $\mathrm{Au}-\mathrm{Cu}$ alloy nanocrystal. (c,d) HRTEM images of the parts marked in $\mathbf{b}$. (e) The corresponding selected-area electron diffraction pattern with the electron beam directed along the fivefold axis. The circles correspond to electron diffractions from the $\{111\}$ planes while the boxes correspond to those from the $\{200\}$ planes. (f) STEM image of a typical pentacle nanocrystal. $(\mathbf{g}, \mathbf{h})$ STEM-EDX elemental mapping image of $(\mathbf{g}) \mathrm{Cu}$ and $(\mathbf{h}) \mathrm{Au}$ of an individual pentacle $\mathrm{Au}-\mathrm{Cu}$ alloy nanocrystal. (i) The merged image of $\mathbf{f}, \mathbf{g}$ and $\mathbf{h}$. Scale bar, $500 \mathrm{~nm}(\mathbf{a})$ and $50 \mathrm{~nm}(\mathbf{b})$. Scale bar, $2 \mathrm{~nm}(\mathbf{c}, \mathbf{d})$.

Scale bar, $50 \mathrm{~nm}$ in the inset and $\mathbf{f}$.

of pentacle nanocrystals was also examined by X-ray diffraction (XRD) and EDX spectra. As shown in Supplementary Fig. 3, the $\mathrm{XRD}$ peaks of pentacle $\mathrm{Au}-\mathrm{Cu}$ nanocrystals can be indexed as a face-centered cubic $(f c c)$ structure, each of which lies in between that of pure $f c c \mathrm{Au}$ (JCPDS no. 04-0784) and pure $f c c \mathrm{Cu}$ (JCPDS no. 85-1326). Although XRD analysis backs the alloy structure, it remains difficult to deduce atomic content from it. Vegard's law has been found unsuitable in the case of $\mathrm{Cu}$ and $\mathrm{Au}$, because $\mathrm{Cu}$ may take the unusual interstitial position ${ }^{28}$. Supplementary Figure 4 shows the EDX spectrum, which confirms the elements of $\mathrm{Au}$ and $\mathrm{Cu}$ in the products (Mo came from the grids) and semi-quantitatively assesses the atomic percentage of $\mathrm{Au}$ and $\mathrm{Cu}$ to be $86.2 \%$ and $13.8 \%$, respectively. Moreover, the atomic percentage of $\mathrm{Au}$ and $\mathrm{Cu}$ were determined to be $87.4 \%$ and $12.6 \%$ by inductive coupled plasma-atomic emission spectroscopy (ICP-AES), respectively.

Shape evolution. Considering the rarely reported fivefold twinned structure of the as-prepared $\mathrm{Au}-\mathrm{Cu}$ bimetallic nanocrystals, their nucleation and growth pathway is a valuable subject of research. Our investigation started from the TEM (Supplementary Fig. 5) and HRTEM (Fig. 2a,f) images recorded from the samples prepared at different reaction time points. As shown in Fig. 2a; Supplementary Fig. 5a, fivefold twinned seeds emerged at the initial stage of the reaction. The fivefold twinned nanocrystals on the length scale of several nanometers usually take three variants in shape, that is, the rounded decahedron, the Marks decahedron and the star decahedron ${ }^{39}$. According to this classification, the nanocrystals after reacting for $8 \mathrm{~min}$ are rounded decahedrons (Fig. 2a; Supplementary Fig. 5a) and gradually grow into a novel type of larger decahedrons (Fig. 2f; Supplementary Fig. 5b) that falls somewhere between the Marks decahedron and the star decahedron ${ }^{39,40}$. With the extension of reaction time to 20 (Supplementary Fig. 5c) and $30 \mathrm{~min}$ (Supplementary Fig. 5d), more and longer branches protruded from the twinning planes of the decahedral core, and the product became dominated by pentacle nanocrystals with an average branch length of $100 \mathrm{~nm}$. The composition of these decahedral seeds was studied through STEM (Fig. 2b,g) aided by EDX mapping, which shows that both seeds at reaction time points of 8 and 12 min were alloys (Fig. $2 c, d, h, i$ ). As shown by line-scanning profiling analysis, both $\mathrm{Cu}$ and $\mathrm{Au}$ distributed nearly homogeneously across the decahedrons (Fig. 2e,j). Careful ICPAES analysis (Supplementary Table 1) shows that the atomic percentage of $\mathrm{Cu}$ rises from $4.7 \%(8 \mathrm{~min})$ to $12.6 \%$ ( $30 \mathrm{~min})$, upon which some rationale can be established for the formation of decahedral seeds and the following shape evolution.

At the beginning of the reaction, metal precursors were quickly reduced by glucose. This especially applies to $\mathrm{AuCl}_{4}^{-}$, because of the apparently higher redox potential of $\mathrm{AuCl}_{4}^{-}$than $\mathrm{Cu}^{2+}$ $\left(\mathrm{Cu}^{2}+\mathrm{Cu}=0.342 \mathrm{~V}, \mathrm{AuCl}_{4}^{-} / \mathrm{Au}=1.002 \mathrm{~V}\right)$. The quick reaction gave rise to the formation of a large number of small seeds. It was pointed out by Yacamán et al. ${ }^{39}$ that at nanometric sizes (typically $\leq 5 \mathrm{~nm}$ ), the fivefold twinned structures such as icosahedrons and decahedrons tend to be more stable than cuboctahedrons $^{41,42}$. Therefore, these seeds might take the shape of decahedrons as a result of thermodynamic preference. Owing to fast reduction, the amount of $\mathrm{AuCl}_{4}^{-}$ions in the solution declined quickly, while that of $\mathrm{Cu}^{2+}$ ions was still maintained at a relatively high level. Although the formation of decahedral seeds could be supported at the early stage, it became unsustainable at later time points. The growth mode was then dominated by kinetic control and deposition of reduced metal atoms was localized at more reactive sites to enlarge twinning planes, but not much on the facets. We hypothesize that, in our work, the exposed facets are more stable than twin boundaries because of underpotential deposition of $\mathrm{Cu}$ on $\mathrm{Au}$ seeds, similar to the report on controlling the shape of $\mathrm{Au}$ nanostructures via $\mathrm{Ag}^{+}$ions by Personick et al. ${ }^{43}$ At this growth stage, the proportion that $\mathrm{Cu}^{2+}$ ions contributed augmented over time, which is supported by the gradual increase of $\mathrm{Cu}$ content in the products. Because of the strong capping effect of amine residues on the apex $(\{110\}$ facets on the top and the bottom) of decahedral seeds ${ }^{40}$, the growth 

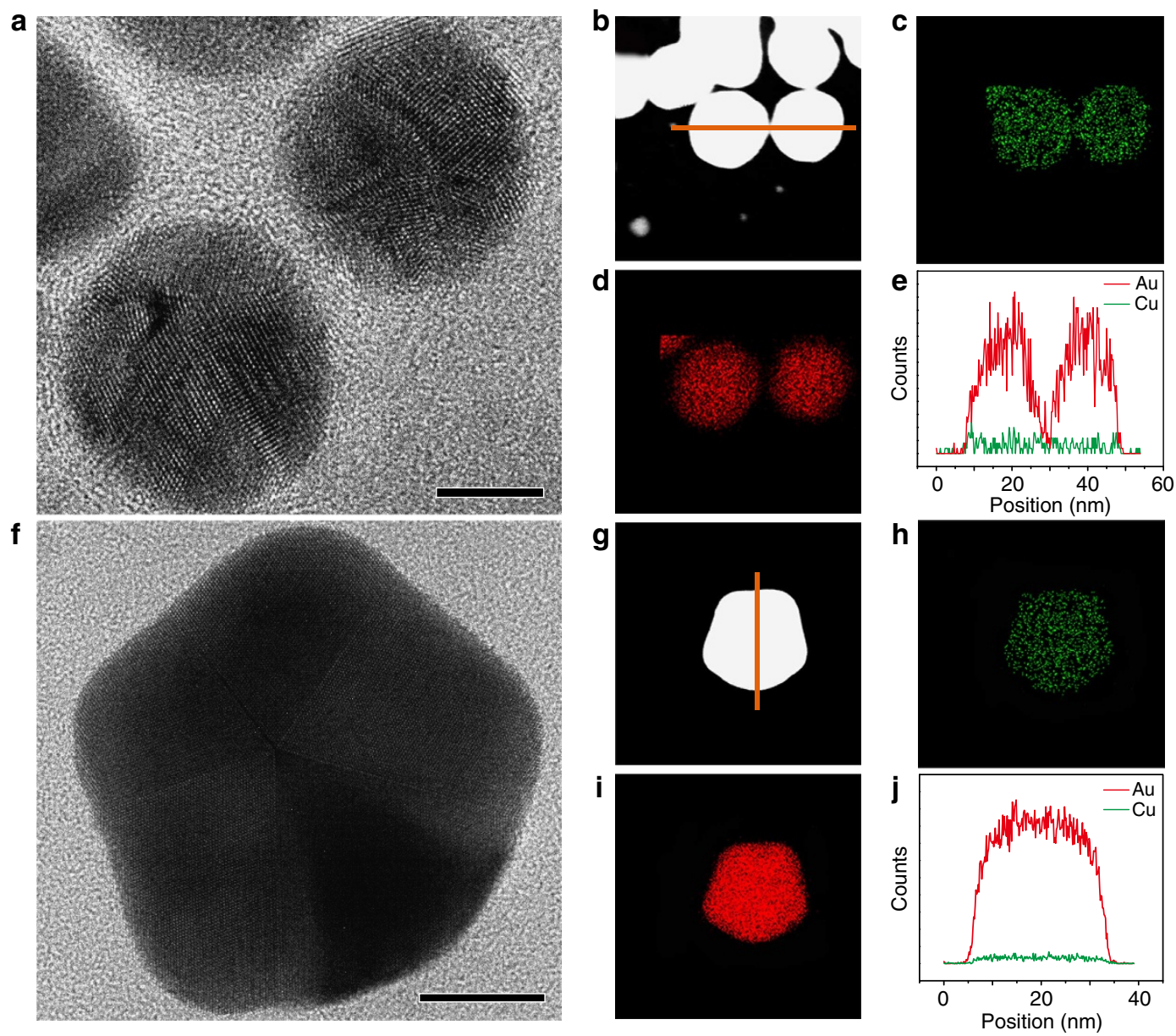

Figure 2 | Characterization of decahedral seeds obtained at $\mathbf{8}$ and $\mathbf{1 2} \mathbf{~ m i n . ~ ( a , f ) ~ H R T E M ~ i m a g e s ~ o f ~ r o u n d e d ~ d e c a h e d r o n s ~ o b t a i n e d ~ a t ~} 8$ min and a decahedral seed obtained at $12 \mathrm{~min}$. (b,g) STEM images of decahedral seeds obtained at 8 and 12 min, respectively. (c,d,h,i) STEM-EDX elemental mapping image of $(\mathbf{c}, \mathbf{h}) \mathrm{Cu}$ and $(\mathbf{d}, \mathbf{i}) \mathrm{Au}$ of decahedral seeds obtained at 8 and $12 \mathrm{~min}$. (e,j) Elemental line-scanning profiles along the direction marked by orange lines in $\mathbf{b}$ and $\mathbf{g}$, respectively. Scale bar, $10 \mathrm{~nm}(\mathbf{a})$ and $20 \mathrm{~nm}(\mathbf{f})$.

along twining planes was more selective to the five edges to form pentacle structures, even at a cost of extra strain energy, rather than to the apex to form nanorods. An implication of the asynchronous reduction of two metal precursors is that the $\mathrm{Au}$ content might be higher inside than outside, which would give rise to an Au-rich core. However, we did not observe it (Fig. If-i) probably because of the diffusion of newly reduced (and reactive) $\mathrm{Cu}$ atoms from outward to inward. The diffusion of one metal into another is a plausible mechanism to reform the nanocrystals into alloys ${ }^{29}$.

Formation mechanism. To explore the mechanism involved in the formation of pentacle $\mathrm{Au}-\mathrm{Cu}$ alloy nanocrystals, we devised a set of experiments using the standard procedure, except for the amount or type of the capping agent or reducing agent. Supplementary Fig. 6a,b shows that the products are highly sensitive to the amount of capping agent. With less HDA (30 mg), the products turned to be polyhedrons (Supplementary Fig. 6a). In contrast, as the amount of HDA was increased to $90 \mathrm{mg}$, the nanorod network (Supplementary Fig. 6b) evolved. While only a small amount of HDA is involved in the reaction, the addition of metal ions to the seeds will be faster, giving rise to nearly isotropic growth in all directions and eventually the formation of polyhedrons. On the contrary, with sufficient HDA, growth is restricted in many directions on the decahedral seeds except for the direction along the twinning plane, as a result of capping. Then the growth of branches overwhelms other places, leading to a nanorod network with unrestrained stretching of the branches $^{27}$. Similar to the concentration of HDA, the amount of glucose (the reducing agent) was also found to play an important role in controlling the morphology of the $\mathrm{Au}-\mathrm{Cu}$ alloy nanocrystals. As illustrated in Supplementary Fig. 7, neither too much nor too little glucose could generate a suitable reduction rate to obtain pentacle nanocrystals in high purity. Besides, we investigated the effect of chain length of the capping agent on the final shape of products. As shown in Supplementary Fig. 6c, when dodecylamine served as the capping agent, irregular-shaped nanocrystals dominated the product. This is primarily because dodecylamine also has a reducing effect so that the nucleation process will occur at room temperature when the solution undergoes magnetic stirring overnight. The aforementioned analysis was further proved by the use of octadecylamine (ODA). As shown in Supplementary Fig. 6d, because of the similar capping effect of ODA with HDA, the pentacle structures appeared again when equal amount of ODA was added into the vial instead of HDA. For this bimetallic system, the $\mathrm{Au} / \mathrm{Cu}$ molar ratio was confirmed to be a main factor in shaping the final products. Supplementary Figure 8 shows TEM images of the products obtained under the standard reaction condition, except that different $\mathrm{Au} / \mathrm{Cu}$ molar ratios of precursors were used. The pentacle shape could only be preserved when the ratio is between 
$11: 9$ and $2: 3$ (the standard value is $1: 1$ ). However, the percentage of $\mathrm{Cu}$ could still be tuned from 4.0 to $17.5 \%$ (Supplementary Fig. $8 \mathrm{~d}, \mathrm{e})$ as the molar ratio is changed from 11:9 to $2: 3$, indicating that the growth mode of pentacle products is rather accommodating. None of the other experiments could yield welldefined pentacle nanocrystals. Specifically, pure $\mathrm{Au}$ and pure $\mathrm{Cu}$ precursors led to the formation of sphere-like $\mathrm{Au}$ particles and cube-like $\mathrm{Cu}$ particles, respectively. Other intermediate molar ratios $(3: 1,3: 2,11: 9,2: 3,1: 2$ and 1:5), however, either gave rise to broken pentacle nanocrystals (resembling multipods), dendritic nanocrystals or a mixture of various shapes. It is believed that $\mathrm{Au} / \mathrm{Cu}$ molar ratio of precursors is strongly related to both the nucleation and growth kinetics, and therefore the final morphology of products.

Size control. Beyond the standard synthesis, we realized size control of the products, especially those with smaller dimensions. In the practice, we held the strategy of shortening the reaction time and inducing additional HDA (see Methods for detailed procedures). The drop in reaction time can cut the size of decahedral seeds. The injection of HDA, in essence, can slow down the reaction rate after the formation of seeds, and therefore increase the selective growth of branches. Figure $3 a-d$ shows typical TEM images of individual pentacle $\mathrm{Au}-\mathrm{Cu}$ bimetallic nanocrystals with sizes of $\sim 45,70,100$ and $200 \mathrm{~nm}$, respectively. The four HRTEM images (Fig. 3e-h) show the corresponding branch ends of the products with different sizes. The width of branches generally increases with the overall size, while the fivefold twinned structure is largely preserved. The high-index feature is found to be definite, and stepped edges can be even more clearly identified owing to shorter branches than the standard products, as shown by higher magnification HRTEM images of the 45-nm and 100-nm products (Supplementary Fig. 9). We have partially assigned the exposed high-index facets and found multiple sets of indices. The 45-nm product was chosen for EDX mapping analysis and the alloy structure was still confirmed (Supplementary Fig. 10a-d). Line-scanning profiles along different directions show that $\mathrm{Cu}$ and $\mathrm{Au}$ were uniformly distributed (Supplementary Fig. 10e,f).
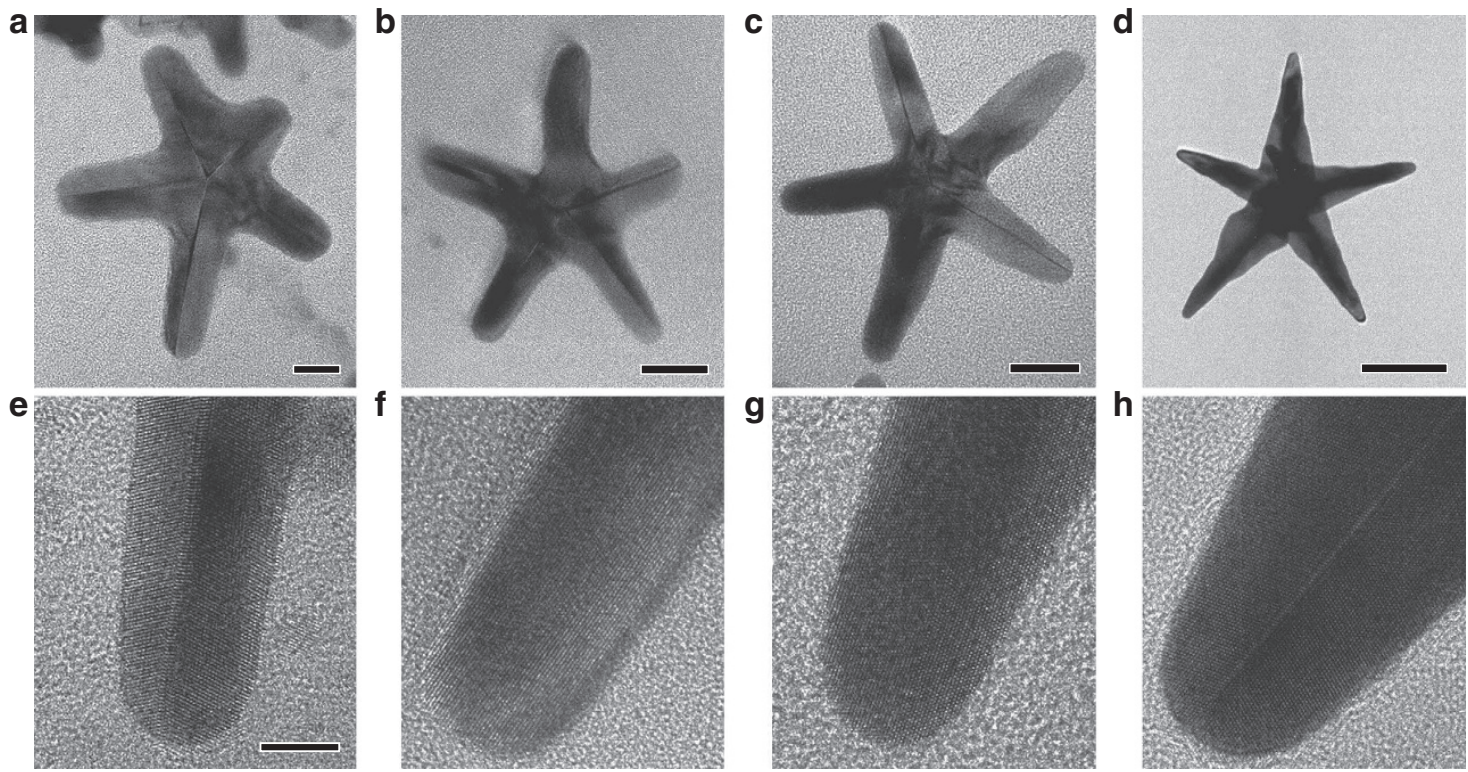

Figure 3 I TEM and HRTEM images of pentacle Au-Cu bimetallic nanocrystals with different sizes. (a-d) TEM images of individual pentacle Au-Cu alloy nanocrystals with sizes of $45,70,100$ and $200 \mathrm{~nm}$, respectively. (e-h) HRTEM images of the corresponding branches in a-d. Scale bar, 10,20 , 20 and $50 \mathrm{~nm}$ (a-d), respectively. Scale bar, $5 \mathrm{~nm}(\mathbf{e})$, which is also used for $\mathbf{f}, \mathbf{g}$ and $\mathbf{h}$. 
a

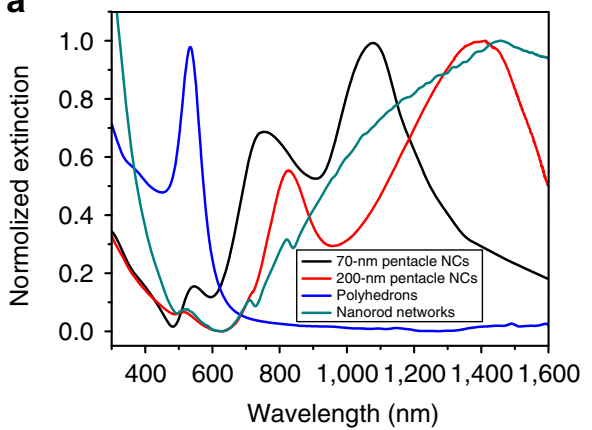

d

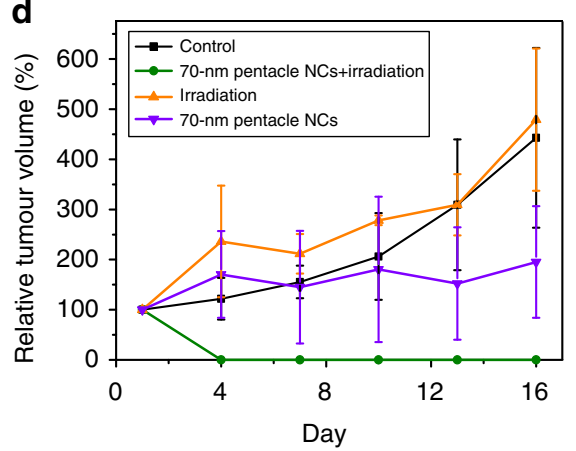

b

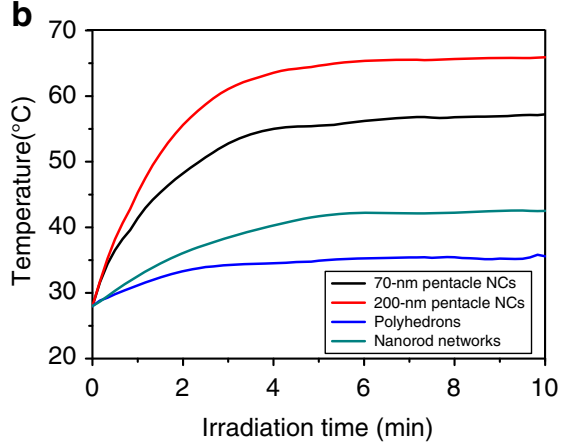

e

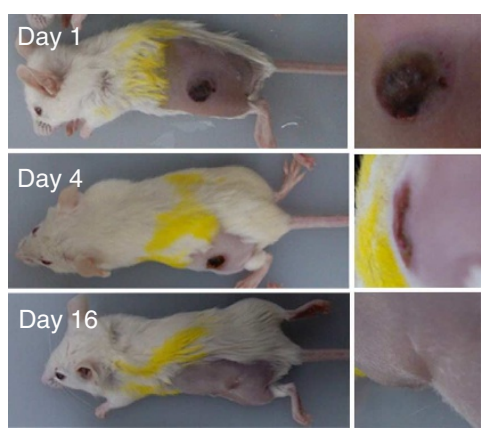

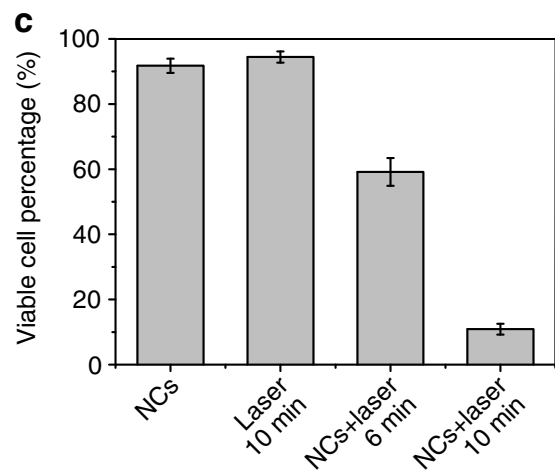

$\mathbf{f}$

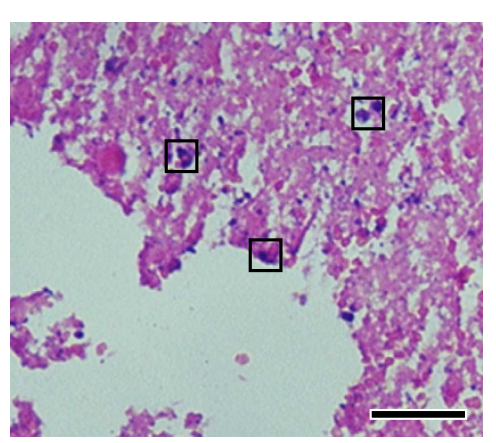

Figure 4 | Plasmonic properties of pentacle Au-Cu alloy nanocrystals and their applications in photothermal therapy. (a) Extinction spectra of aqueous suspensions of $\mathrm{Au}-\mathrm{Cu}$ alloy nanocrystals with different shapes. (b) Photothermal effect of these Au-Cu alloy nanocrystals. The plot of temperature versus time was recorded upon irradiation by an $808-\mathrm{nm}$ laser $\left(1 \mathrm{Wcm}^{-2}\right.$ ). (c) Viability of $4 \mathrm{~T} 1$ murine breast tumour cells incubated under different conditions (with pentacle Au-Cu alloy nanocrystals or laser or both) for a specified period of time. The concentration of pentacle Au-Cu alloy nanocrystals was $10 \mu \mathrm{g} \mathrm{ml}^{-1}$, and the power density of the laser was $1 \mathrm{~W} \mathrm{~cm}{ }^{-2}$. The incubation time of cells treated with only nanocrystals was $6 \mathrm{~h}$. (d) The tumour growth curves of different groups of mice after treatment. The tumour volumes were normalized to their initial sizes. Laser wavelength $=808 \mathrm{~nm}$; power density $=1 \mathrm{~W} \mathrm{~cm}^{-2}$; irradiation time $=5 \mathrm{~min}$. Error bars were based on s.d. of six mice per group. (e) Photographs of representative $4 \mathrm{~T} 1$ tumour-bearing mice 1, 4 and 16 days after the photothermal treatment in the 70-nm pentacle nanocrystals + irradiation group. (f) Haematoxylin and eosin-stained tumour sections collected from a typical mice after 4-day photothermal treatment in the 70-nm pentacle nanocrystals + irradiation group. Characterized by loose structure and cells with pyknotic nuclei, necrosis was seen (black boxes in f). Scale bar, $20 \mu \mathrm{m}$ (f).

(power density $=1 \mathrm{~W} \mathrm{~cm}^{-2}$ ). By comparison, the exposure of $4 \mathrm{~T} 1$ cells to $10 \mu \mathrm{g} \mathrm{ml}^{-1}$ of pentacle nanocrystals with the presence of irradiation led to a quick decline in viability. Supplementary Fig. 11a-c shows micrographs of the $4 \mathrm{~T} 1$ cells after 0,6 and $10 \mathrm{~min}$ of irradiation, respectively. The dead cells are stained with propidium iodide. It was found that $>40 \%$ of the cells were killed after $6 \mathrm{~min}$ of irradiation and nearly $90 \%$ were killed after 10 min of laser treatment (Fig. 4c).

For in vivo PTT study, we employed subcutaneous 4T1 xenograft model in $\mathrm{BALB} / \mathrm{c}$ mice to study the efficacy of photothermal treatment of $70-\mathrm{nm}$ pentacle nanocrystals. Twenty-four tumour mice were randomly and evenly divided into four groups, which were the control group with no particular treatment, the group with intratumoral injection of $70-\mathrm{nm}$ pentacle nanocrystals and irradiation of NIR laser $(808 \mathrm{~nm}$, $1 \mathrm{~W} \mathrm{~cm}^{-2}$ ) for $5 \mathrm{~min}$, the group with only irradiation and the group with only particle injection. Supplementary Figure 12 shows infrared radiation thermal images of tumour-bearing $\mathrm{BALB} / \mathrm{c}$ mice at different time points of irradiation, which confirms the in vivo photothermal effect. Supplementary Figure 13 shows photographs of mice and their close-up views of tumours in four differently treated groups at day 4, with one representative mouse from each group. It is clearly observed that the thorough regression of tumour was only found in the photothermal group. Figure $4 \mathrm{~d}$ compares the change in relative tumour volume (that is, normalized against initial values before treatment) on $\mathrm{BALB} / \mathrm{c}$ mice along with feeding time. In the control experiment, the tumours grew exponentially to $>3$ times larger in 2 weeks than those in 1 day. As shown by red and purple segmental lines, the tumours from both the irradiation-only and injection-only groups enlarged in volume, with some fluctuations. These experiments ruled out the possibility that any single factor can effectively suppress tumour growth. The group of mice that received both nanocrystal injection and irradiation, however, was rid of tumours 4 days after the treatment (Fig. 4e; Supplementary Fig. 13).

To understand the effect of PTT at a microscopic perspective, we studied the existence of cancer cells in the tumours of differently treated mice by tissue slicing and staining. Since welldifferentiated glandular cancer cells are characterized by a large cell nucleus, which is one to five times larger than those of the normal cells and abundant cytoplasm, it is not difficult to identify them under the optical microscope. In our experiments, densely distributed cancer cells could be found in tumour sections collected from non-photothermally treated mice (Supplementary Fig. $14 \mathrm{a}-\mathrm{c}$ ). They are with visibly big nuclei that are usually darker than the cytoplasm. Figure $4 \mathrm{f}$, which is a partially enlarged view of Supplementary Fig. 14d, however, shows separation of pyknotic nuclei from the cytoplasm (marked by black boxes). This result demonstrates necrosis of the tumour and thus the effectiveness of photothermal therapy to $4 \mathrm{~T} 1$ tumour. We also examined the influence of injected metal nanocrystals on major organs of the mice. As shown in Supplementary Fig. 15, no obvious abnormality was found from haematoxylin and 
eosin-stained images of the major organs of the as-treated mice at day 1 , with those of the untreated mice as a benchmark.

Encouraged by the high NIR absorbance and strong PTT efficacy of pentacle nanocrystals, we attempted delivering the 70$\mathrm{nm}$ pentacle $\mathrm{Au}-\mathrm{Cu}$ nanocrystals to tumours via systemic intravenous injection. The surface of pentacle nanocrystals was coated with a monolayer of polyethylene glycol (PEG), which allows a long circulation time of pentacle nanocrystals in the blood stream and accumulation in the tumour. Two groups of mice (three mice per group), which received either an intravenous injection of PEGylated nanocrystals $\left(1 \mathrm{mg} \mathrm{ml}^{-1}, 200 \mu \mathrm{l}\right)$ or saline $\left(2 \mathrm{mg} \mathrm{ml}^{-1}, 20 \mu \mathrm{l}\right)$, were compared for photothermal heating efficiency. At 1 day post injection, both groups of mice were irradiated by a NIR laser for $6 \mathrm{~min}$ and the temperature change in the tumour area under NIR irradiation was recorded. The tumour surface temperatures rapidly increased (up to $6.14 \pm 0.86^{\circ} \mathrm{C}$ ) in the group treated with PEGylated nanocrystals, but the control group showed little change (Supplementary Fig. 16). The passive tumour accumulation of PEGylated nanocrystals after intravenous injection could be attributed to the enhanced permeability and retention effect of tumours ${ }^{45}$, indicating the tumour diagnostic and therapeutic potential of pentacle nanocrystals.

Catalytic properties. Owing to the synergistic effect of the two metal components, large surface area of the branches and possibly high-index facets, the pentacle $\mathrm{Au}-\mathrm{Cu}$ alloy nanocrystals are expected to exhibit excellent catalytic effect towards a wide range of reactions $s^{30,33}$. We adopted the reduction of $p$-nitrophenol to $p$-aminophenol by $\mathrm{NaBH}_{4}$ as a model reaction to evaluate the catalytic activity of differently sized products ${ }^{46-48}$. To set points of reference, polyhedrons (Supplementary Fig. 6a), nanorod network (Supplementary Fig. 6b) and conventional citrate-coated $\mathrm{Au}$ nanoparticles (Supplementary Fig. 17) were tested under the same conditions. The well-established reaction has been reported to be catalysed by a variety of noble metal nanocrystals and the reaction kinetics can be monitored by spectroscopic measurements. Figure 5a shows a typical set of extinction spectra recorded at different time points of the reaction, which has been normalized against the extinction intensity before the reaction. Under a neutral or acidic condition, $p$-nitrophenol solution should exhibit a strong absorption peak at $317 \mathrm{~nm}$. With the addition of $\mathrm{NaBH}_{4}, p$-nitrophenolate ions will take the lead as the alkalinity of the solution increases and then the absorption peak redshifts to $\sim 400 \mathrm{~nm}$ (ref. 49). This analysis explains the peak position at the initial time point. After the addition of catalysts, a new peak at $315 \mathrm{~nm}$ for $p$-aminophenol appeared, and the intensity of the absorption peak at $400 \mathrm{~nm}$ gradually lowered as increasing amount of $p$-nitrophenol was reduced to $p$-aminophenol. Because the peak at $400 \mathrm{~nm}$ dominated for most of the time, it is reasonable to derive the concentration of $p$-nitrophenolate ions from absorbance at $400 \mathrm{~nm}$ and thus to investigate the reaction kinetics. It should be noted that all experiments were accomplished with fixed concentrations of $p$-nitrophenol $\left(1.4 \times 10^{-4} \mathrm{M}\right)$ and $\mathrm{NaBH}_{4}\left(4.2 \times 10^{-2} \mathrm{M}\right)$. Because the concentration of $\mathrm{NaBH}_{4}$ is comparatively enormous compared with $p$-nitrophenol, it is considered as a constant during the reaction. Therein, we assume that the pseudo-first-order kinetics with respect to $p$-nitrophenol (or $p$-nitrophenolate) can be applied, which is supported by the linear relationship between the logarithm of the normalized extinction intensity at $400 \mathrm{~nm}$ and time (minus adsorption time). Therefore, we are able to calculate the apparent reaction rate constants $\left(k_{\text {app }}\right)$ in reaction systems with different concentrations and types of metal nanocrystals using the previously reported method ${ }^{47,48}$. The apparent rate constant versus mass concentration $(M)$
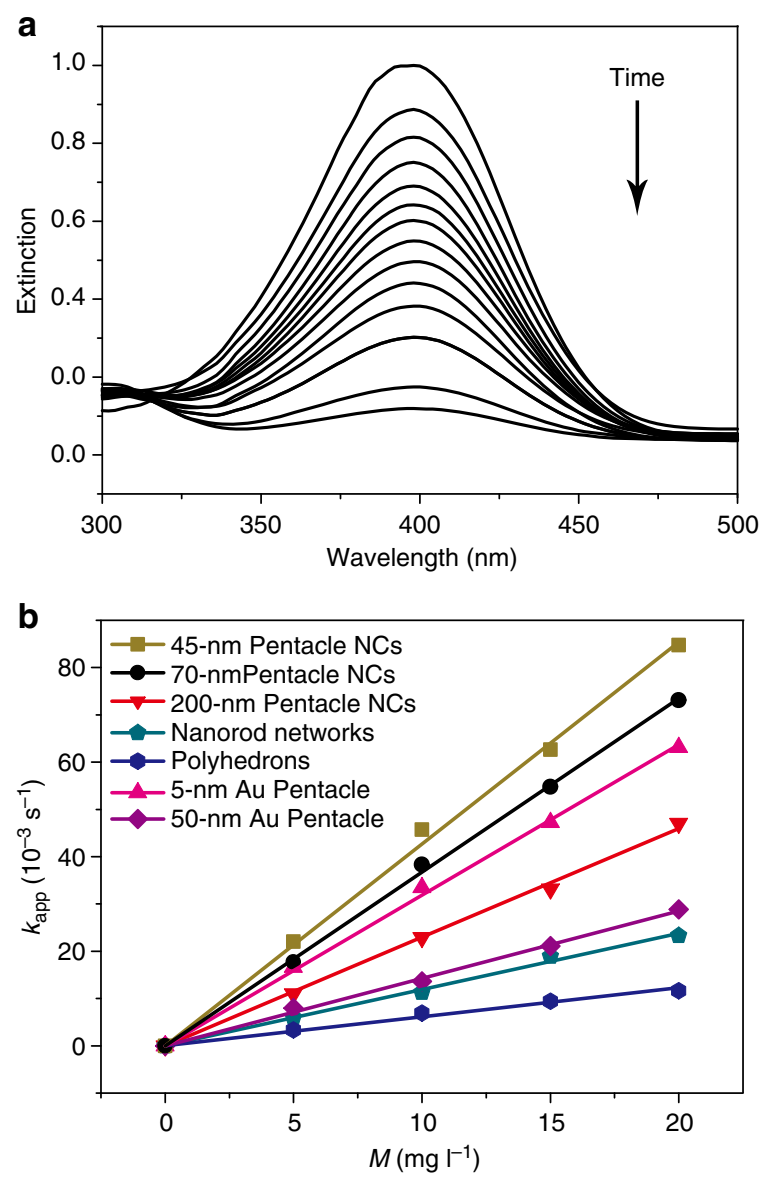

Figure 5 | Catalytic properties of pentacle $\mathrm{Au}-\mathrm{Cu}$ alloy nanocrystals. (a) The extinction spectra recorded at different reaction time points, indicating the disappearance of the peak for $p$-nitrophenol owing to the reduction of $-\mathrm{NO}_{2}$ group into $-\mathrm{NH}_{2}$ group. (b) Plots of the apparent rate constants $\left(k_{\mathrm{app}}\right)$ as a function of the mass concentration $(M)$, relating to the use of different types of $\mathrm{Au}-\mathrm{Cu}$ bimetallic nanocrystals and conventional $\mathrm{Au}$ nanoparticles as catalysts for the reduction of $p$-nitrophenol into p-aminophenol by $\mathrm{NaBH}_{4}$.

appears in a linear relationship (Fig. 5b). To exclude the influence of volume change and thus different concentrations of nanocrystals, we further derived the slope of the line $\left(k_{1}\right)$ from the equation of first-order kinetics (see equation (1)), which reflects the intrinsic catalytic activity.

$$
-\mathrm{d} c_{\mathrm{t}} / \mathrm{d} t=k_{\mathrm{app}} c_{t}=k_{1} M c_{\mathrm{t}}
$$

The slope $\left(k_{1}\right)$ related to 200 -nm pentacle nanocrystals, nanorod networks and polyhedrons were determined to be $2.30 \times 10^{-3}$, $1.19 \times 10^{-3}$ and $0.61 \times 10^{-3} 1 \mathrm{~s}^{-1} \mathrm{mg}^{-1}$, respectively. Therefore, $200-\mathrm{nm}$ pentacle nanocrystals enjoyed higher level of catalytic activity than $\mathrm{Au}-\mathrm{Cu}$ bimetallic nanocrystals in the other two shapes. As shown in Fig. 5b, although conventional $\mathrm{Au}$ nanoparticles appeared less active than 200-nm pentacle nanocrystals at a size of $50 \mathrm{~nm}$, they gave substantially higher activity with a smaller dimension ( $5 \mathrm{~nm}$ in size), which was higher than what the 200-nm pentacle nanocrystals could offer. The comparative study on size dependence of catalytic activities of pentacle nanocrystals shows that $k_{1}$ climbed up from $2.30 \times 10^{-3}$ to $3.67 \times 10^{-3}$ and $4.27 \times 10^{-3} 1 \mathrm{~s}^{-1} \mathrm{mg}^{-1}$, respectively, as the size was reduced to 70 and $45 \mathrm{~nm}$. Obviously, the activities of 70-nm and 45-nm pentacle nanocrystals were both higher than 5-nm conventional Au nanoparticles. It can thus be concluded 
that the advantages brought about by the synergistic effect, twinning interfaces and possibly the high-index feature could overcome significantly smaller surface area/volume ratio. We further addressed the relationship between apparent reaction rate and surface area concentration to discern specific activities with respect to surface area. The surface areas of different types of $\mathrm{Au}-$ $\mathrm{Cu}$ bimetallic nanocrystals were calculated on schematic models (Supplementary Fig. 18). It was interesting to find that the specific activity per area of pentacle nanocrystals dropped with size (Supplementary Fig. 19). An intuitive explanation may be that, larger pentacle nanocrystals had a bigger portion of exposed highindex facets on branches, which might serve as highly active sites for catalysis. However, the specific reaction rate constant with regard to 45-nm pentacle nanocrystals was still higher than those of the other two kinds of $\mathrm{Au}-\mathrm{Cu}$ bimetallic nanocrystals. This may illustrate that a small proportion of exposed high-index facets could promote total activity towards the reaction.

\section{Discussion}

In summary, we report a facile aqueous synthetic route to pentacle $\mathrm{Au}-\mathrm{Cu}$ alloy nanocrystals with fivefold twinning. Through manipulating the reaction time and the addition of capping agent, we obtained pentacle-shaped products with tunable size from 45 to $200 \mathrm{~nm}$. According to electron microscopic analysis of the samples obtained at different reaction time points, decahedral seeds formed at the initial stage of the reaction, and then multiple branches protruded parallel to the twinning planes. Study on the formation mechanism revealed that unduly large or small amounts of capping agent or reducing agent might prevent the formation of well-defined pentacle nanocrystals and create other shapes, including polyhedrons and nanorod networks. The as-prepared pentacle nanocrystals displayed strong LSPR properties in the NIR region, which created an obvious photothermal effect. It was demonstrated that upon NIR irradiation, 4T1 murine breast tumour cells incubated with 70$\mathrm{nm}$ pentacle nanocrystals were effectively killed. Further in vivo study showed the photothermal destruction of $4 \mathrm{~T} 1$ murine breast tumour grown on $\mathrm{BALB} / \mathrm{c}$ mice. In catalysis tests, pentacle nanocrystals exhibited higher catalytic activity than polyhedrons and nanorod networks towards a model reaction of reducing p-nitrophenol by $\mathrm{NaBH}_{4}$. Although they appeared less competitive in activity than $5-\mathrm{nm}$ conventional citrate-coated $\mathrm{Au}$ nanoparticles at the size of $200 \mathrm{~nm}$, pentacle nanocrystals were more active than 5-nm conventional $\mathrm{Au}$ nanoparticles with reduced sizes to 70 and $45 \mathrm{~nm}$. We believe this piece of work can provide an insight into the aqueous phase synthesis of bimetallic nanocrystals and promote their applications in biomedicine and catalysis.

\section{Methods}

Chemicals and materials. Cupric chloride dihydrate $\left(\mathrm{CuCl}_{2} \cdot 2 \mathrm{H}_{2} \mathrm{O}, 99 \%\right)$, tetrachloroaurate trihydrate $\left(\mathrm{HAuCl}_{4} \cdot 3 \mathrm{H}_{2} \mathrm{O}, 99 \%\right)$ and glucose $(\alpha$ or $\beta$ form) were purchased from Sinopharm Chemical Reagent Co. Ltd (Shanghai, China). HDA (90\%) was obtained from Sigma-Aldrich. All the vials were made from borosilicate glass, with a black phenolic-moulded screw cap and polyvinyl-faced pulp liner. Ultrapure Millipore water (18.2 M $\Omega$ ) was used as the solvent throughout.

\section{Synthesis of 200-nm pentacle Au-Cu alloy nanocrystals. In a standard} synthesis of pentacle $\mathrm{Au}-\mathrm{Cu}$ alloy nanocrystals, $0.3 \mathrm{ml}$ of aqueous $\mathrm{CuCl}_{2} \cdot 2 \mathrm{H}_{2} \mathrm{O}$ $(100 \mathrm{mM}), 0.3 \mathrm{ml}$ of aqueous $\mathrm{HAuCl}_{4} \cdot 3 \mathrm{H}_{2} \mathrm{O}(100 \mathrm{mM}), 45 \mathrm{mg}$ of $\mathrm{HDA}, 0.28 \mathrm{ml}$ of aqueous glucose $(1 \mathrm{M})$ and $4 \mathrm{ml}$ of water were added in a $20-\mathrm{ml}$ vial at room temperature. After the vial had been capped, the solution was magnetically stirred at room temperature overnight. The capped vial was then transferred into an oil bath and heated at $100^{\circ} \mathrm{C}$ for $30 \mathrm{~min}$ under magnetic stirring. As the reaction proceeded, the solution changed its colour from kelly green to brown. To prepare samples for electron microscopy characterizations, the pentacle nanocrystals were centrifugated at 10,000 r.p.m. for $8 \mathrm{~min}$ and washed with water three times and ethanol twice to remove excess precursor, HDA and glucose. As discussed in the main text, the shapes of the $\mathrm{Au}-\mathrm{Cu}$ nanocrystals could be controlled to polyhedrons and nanorod networks by simply adjusting the concentrations of HDA.

Controlling the size of pentacle Au-Cu alloy nanocrystals. In a synthesis of 45 $\mathrm{nm}$ pentacle $\mathrm{Au}-\mathrm{Cu}$ alloy nanocrystals, $0.3 \mathrm{ml}$ of aqueous $\mathrm{CuCl}_{2} \cdot 2 \mathrm{H}_{2} \mathrm{O}(100 \mathrm{mM})$ $0.3 \mathrm{ml}$ of aqueous $\mathrm{HAuCl}_{4} \cdot 3 \mathrm{H}_{2} \mathrm{O}(100 \mathrm{mM}), 45 \mathrm{mg}$ of $\mathrm{HDA}, 0.28 \mathrm{ml}$ of aqueous glucose $(1 \mathrm{M})$ and $4 \mathrm{ml}$ of water were added in a $20-\mathrm{ml}$ vial at room temperature. After the vial had been capped, the solution was magnetically stirred at room temperature overnight. The capped vial was then transferred into an oil bath and heated at $100^{\circ} \mathrm{C}$ for $3 \mathrm{~min}$. Then $30 \mathrm{mg}$ HDA was added into the reaction solution at $100^{\circ} \mathrm{C}$. The reaction was stopped and the solution was cooled down using iced water when its colour changed from kelly green to brown. The 70-nm and 100-nm pentacle $\mathrm{Au}-\mathrm{Cu}$ alloy nanocrystals were prepared under the same condition with 45 -nm ones, except for the heating time before the addition of HDA extended to 4 and $5 \mathrm{~min}$, respectively.

Characterizations. SEM images were obtained with a SEM (JSM-6700F) operated at $5 \mathrm{kV}$. TEM and HRTEM images were collected on a JEOL ARM-200F fieldemission transmission electron microscope operating at $200 \mathrm{kV}$ accelerating voltage. XRD characterization was performed using a Philips X'Pert Pro X-ray diffractometer with a monochromatized $\mathrm{Cu} \mathrm{K} \alpha$ radiation source and a wavelength of $0.1542 \mathrm{~nm}$. ICP-AES (Atomscan Advantage, Thermo Jarrell Ash, USA) was used to determine the concentration of $\mathrm{Au}$ and $\mathrm{Cu}$. Extinction spectra were recorded on a U-4100 at room temperature (Hitachi, Japan).

Photothermal effect measurement. To study the photothermal effect induced by the NIR laser, $250-\mu \mathrm{l}$ solutions containing $10 \mu \mathrm{g} \mathrm{ml}^{-1} \mathrm{Au}-\mathrm{Cu}$ alloy nanocrystals with three different sizes or shapes were irradiated by a NIR laser $(808 \mathrm{~nm}$, $\left.1 \mathrm{~W} \mathrm{~cm}^{-2}\right)$. The temperatures of the solutions were monitored by a thermocouple microprobe $(\varphi=0.5 \mathrm{~mm})$ submerged in the solution in a hole of a 96-well plate. The probe was placed at such a position that the direct irradiation of the laser on the probe was avoided.

Apoptosis assay. 4T1 cells were cultured in RPMI 1640 medium in 96-well plates. The cell density was $1 \times 10^{5}$ cells per well. After being seeded for $18 \mathrm{~h}$, the media were replaced by culture media containing $10 \mu \mathrm{g} \mathrm{ml}^{-1}$ pentacle $\mathrm{Au}-\mathrm{Cu}$ alloy nanocrystals. The incubations were carried out at $37^{\circ} \mathrm{C}$ in $5 \% \mathrm{CO}_{2}$ atmosphere for $6 \mathrm{~h}$. After incubation, cell viabilities were measured by the standard MTT assay, a colorimetric assay based on the ability of viable cells to reduce 3-[4,5-dimethylthiazol-2-yl]-2,5-diphenyltetrazolium bromide. The survival rate and the error bar are shown in Fig. 4c (the case of incubating with nanocrystals only).

Photothermal killing of cancer cells. After incubation with $10 \mu \mathrm{g} \mathrm{ml}^{-1}$ pentacle $\mathrm{Au}-\mathrm{Cu}$ alloy nanocrystals, $4 \mathrm{~T} 1$ cells were exposed to a $1-\mathrm{W} \mathrm{cm}^{-2} 808-\mathrm{nm}$ laser for various periods to induce photothermal cell damage. For comparison, we also put the $4 \mathrm{~T} 1$ cells under the same laser condition for $10 \mathrm{~min}$. To identify the cell viability, the dead cells were stained with propidium iodide (Supplementary Fig. 11). Cell viabilities were also measured by the standard MTT assay.

Animal model. BALB/c mice ( $\sim 20 \mathrm{~g}$ ) were used under protocols approved by the Xiamen University Laboratory Animal Center. For the 4T1 murine breast tumour model, about $5 \times 10^{6} 4 \mathrm{~T} 1$ cells in $60 \mu \mathrm{l}$ of phosphate-buffered saline were injected subcutaneously into the flank of the mouse. The mice were used when their tumour volumes reached $60-70 \mathrm{~mm}^{3}$

In vivo photothermal therapy. An optical fibre-coupled 808-nm high power diode-laser was used to irradiate tumours during experiments. For photothermal treatment, $\mathrm{BALB} / \mathrm{c}$ mice bearing $4 \mathrm{~T} 1$ murine breast tumours were intratumorally injected with $\mathrm{Au}-\mathrm{Cu}$ alloy nanocrystals $\left(30 \mu \mathrm{lof} 1 \mathrm{mg} \mathrm{ml}^{-1}\right.$ solution for each mouse) at the power density of $1 \mathrm{~W} \mathrm{~cm}^{-2}$ for $5 \mathrm{~min}$. Infrared thermal images were taken by an ICI 7320 Pro thermal imaging camera. The tumour sizes were measured by a caliper every other day and calculated as volume $=$ (tumour length) $\times(\text { tumour width })^{2} / 2$. Relative tumour volumes were calculated as $V / V_{0}\left(V_{0}\right.$ is the tumour volume when the treatment was initiated).

Tissue slicing and staining. To obtain tissue sections, three mice from each group were killed at different days. Tumours or major organs from these mice were fixed in $10 \%$ neutral-buffered formalin, processed routinely into paraffin, sectioned at $5 \mu \mathrm{m}$, stained with haematoxylin and eosin and then examined by a digital microscope. For Fig. 4f; Supplementary Fig. 14, tumours were collected at day 4 . For Supplementary Fig. 15, tissues were obtained at day 1, from heart, liver, kidney, lung, spleen stomach and pancreas.

In vivo thermographic profiling. Mice bearing $4 \mathrm{~T} 1$ tumours 1 day post intravenous injection with $200 \mu \mathrm{l} \mathrm{of} 1 \mathrm{mg} \mathrm{ml}^{-1}$ PEGylated pentacle $\mathrm{Au}-\mathrm{Cu}$ alloy nanocrystals or saline were anaesthetised and exposed to be irradiated by a NIR laser 
$\left(808 \mathrm{~nm}, 1 \mathrm{~W} \mathrm{~cm}^{-2}\right)$ for $6 \mathrm{~min}$. During irradiation, the tumour surface temperatures were recorded by an infrared radiation thermal camera.

Testing of catalytic properties. For all experiments, the initial concentrations of p-nitrophenol and $\mathrm{NaBH}_{4}$ were kept at $1.4 \times 10^{-4}$ and $4.2 \times 10^{-2} \mathrm{M}$, respectively. The mass concentrations of $\mathrm{Au}-\mathrm{Cu}$ alloy catalysts were calculated depending on ICP-AES measurement. For polyhedrons and nanorod networks, the atomic percentages of $\mathrm{Cu} / \mathrm{Au}$ were $10.1 \% / 89.9 \%$ and $11.5 \% / 88.5 \%$, respectively. For pentacle nanocrystals, the result is provided in the main text. For accuracy, the extinction caused by the $\mathrm{Au}$ nanoparticles and the $\mathrm{Au}-\mathrm{Cu}$ alloy catalysts was subtracted from all the spectroscopic measurements.

\section{References}

1. Cozzoli, P. D., Pellegrino, T. \& Manna, L. Synthesis, properties and perspectives of hybrid nanocrystal structures. Chem. Soc. Rev. 35, 1195-1208 (2006).

2. Habas, S. E., Lee, H., Radmilovic, V., Somorjai, G. A. \& Yang, P. Shaping binary metal nanocrystals through epitaxial seeded growth. Nat. Mater. 6, 692-697 (2007)

3. Stamenkovic, V. R. et al. Surface site availability improved oxygen reduction activity on $\mathrm{Pt}_{3} \mathrm{Ni}$ (111) via increased surface site availability. Science 315, 493-497 (2007).

4. Ferrando, R., Jellinek, J. \& Johnston, R. L. Nanoalloys: from theory to applications of alloy clusters and nanoparticles. Chem. Rev. 108, 846-904 (2008)

5. Tedsree, K. et al. Hydrogen production from formic acid decomposition at room temperature using a Ag-Pd core-shell nanocatalyst. Nat. Nanotech. 6, 302-307 (2011)

6. Langille, M. R., Zhang, J., Personick, M. L., Li, S. \& Mirkin, C. A. Stepwise evolution of spherical seeds into 20-fold twinned. Science 337, 954-957 (2012).

7. Costi, R., Saunders, A. E. \& Banin, U. Colloidal hybrid nanostructures: a new type of functional materials. Angew. Chem. Int. Ed. 49, 4878-4897 (2010)

8. You, H., Yang, S., Ding, B. \& Yang, H. Synthesis of colloidal metal and metal alloy nanoparticles for electrochemical energy applications. Chem. Soc. Rev. 42, 2880-2904 (2013).

9. Ye, X., Chen, J., Diroll, B. T. \& Murray, C. B. Tunable plasmonic coupling in self-Assembled binary nanocrystal superlattices studied by correlated optical microspectrophotometry and electron microscopy. Nano Lett. 13, 1291-1297 (2013)

10. Oh, M. H. et al. Galvanic replacement reactions in metal oxide nanocrystals. Science 340, 964-968 (2013).

11. Zhang, L. et al. $\mathrm{Cu}^{2+}$-assisted synthesis of hexoctahedral Au-Pd alloy nanocrystals with high-index facets. J. Am. Chem. Soc. 133, 17114-17117 (2011).

12. Zeng, J. et al. Controlling the nucleation and growth of silver on palladium nanocubes by manipulating the reaction kinetics. Angew. Chem. Int. Ed. 51, 2354-2358 (2012).

13. Sneed, B. T., Kuo, C.-H., Brodsky, C. N. \& Tsung, C.-K. Iodide-mediated control of rhodium epitaxial growth on well-defined noble metal nanocrystals: synthesis, characterization, and structure-dependent catalytic properties. J. Am. Chem. Soc. 134, 18417-18426 (2012).

14. Chen, M., Wu, B., Yang, J. \& Zheng, N. Small adsorbate-assisted shape control of Pd and Pt nanocrystals. Adv. Mater. 24, 862-879 (2012).

15. Yang, C.-W. et al. Fabrication of Au-Pd core-shell heterostructures with systematic shape evolution using octahedral nanocrystal cores and their catalytic activity. J. Am. Chem. Soc. 133, 19993-20000 (2011).

16. Liu, X., Wang, D. \& Li, Y. Synthesis and catalytic properties of bimetallic nanomaterials with various architectures. Nano Today 7, 448-466 (2012).

17. Guo, S. et al. FePt and CoPt nanowires as efficient catalysts for the oxygen reduction reaction. Angew. Chem. Int. Ed. 52, 3465-3468 (2013).

18. Wang, H., Chen, L., Feng, Y. \& Chen, H. Exploiting core-shell synergy for nanosynthesis and mechanistic investigation. Acc. Chem. Res. 46, 1636-1646 (2013).

19. Pang, X., Zhao, L., Han, W., Xin, X. \& Lin, Z. A general and robust strategy for the synthesis of nearly monodisperse colloidal nanocrystals. Nat. Nanotech. 8, 426-431 (2013).

20. Grzelczak, M., Pérez-Juste, J., Mulvaney, P. \& Liz-Marzán, L. M. Shape control in gold nanoparticle synthesis. Chem. Soc. Rev. 37, 1783-1791 (2008).

21. Chen, H., Shao, L., Lia, Q. \& Wang, J. Gold nanorods and their plasmonic properties. Chem. Soc. Rev. 42, 2679-2724 (2013).

22. Chang, Y., Lye, M. L. \& Zeng, H. C. Large-scale synthesis of high-quality ultralong copper nanowires. Langmuir 21, 3746-3748 (2005).

23. Lignier, P., Bellabarba, R. \& Tooze, R. P. Scalable strategies for the synthesis of well-defined copper metal and oxide nanocrystals. Chem. Soc. Rev. 41, 1708-1720 (2012)

24. Zhang, D. et al. Synthesis of ultralong copper nanowires for high-performance transparent electrodes. J. Am. Chem. Soc. 134, 14283-14286 (2012).
25. Wu, J., Zang, J., Rathmell, A. R., Zhao, X. \& Wiley, B. J. Reversible sliding in networks of nanowires. Nano Lett. 13, 2381-2386 (2013).

26. Pastoriza-Santos, I., Sánchez-Iglesias, A., Rodríguez-González, B. \& Liz-Marzán, L. M. Aerobic synthesis of nanoplates with intense plasmon resonances. Small 5, 440-443 (2009).

27. Jin, M. et al. Shape-controlled synthesis of copper nanocrystals in an aqueous solution with glucose as a reducing agent and hexadecylamine as a capping agent. Angew. Chem. Int. Ed. 50, 10560-10564 (2011).

28. Liu, Y. \& Walker, A. R. H. Monodisperse gold-copper bimetallic nanocubes: facile one-step synthesis with controllable size and composition. Angew. Chem Int. Ed. 49, 6781-6785 (2010).

29. Chen, W. et al. A seed-based diffusion route to monodisperse intermetallic CuAu nanocrystals. Angew. Chem. Int. Ed. 49, 2917-2921 (2010).

30. Yin, F., Wang, Z. W. \& Palmer, R. E. Controlled formation of massselected Cu-Au core-shell cluster beams. J. Am. Chem. Soc. 133, 10325-10327 (2011).

31. Zhang, H. et al. Facile synthesis of five-fold twinned, starfish-like rhodium nanocrystals by eliminating oxidative etching with a chloride-free precursor. Angew. Chem. Int. Ed. 49, 5296-5300 (2010).

32. Liao, H.-G., Jiang, Y.-X., Zhou, Z.-Y., Chen, S.-P. \& Sun, S.-G. Shape-controlled synthesis of gold nanoparticles in deep eutectic solvents for studies of structurefunctionality relationships in electrocatalysis. Angew. Chem. Int. Ed. 47, 9100-9103 (2008).

33. Zhang, L.-F., Zhong, S.-L. \& Xu, A.-W. Highly branched concave Au/Pd bimetallic nanocrystals with superior electrocatalytic activity and highly efficient SERS enhancement. Angew. Chem. Int. Ed. 52, 645-649 (2013).

34. Zhang, J. et al. Concave cubic gold nanocrystals with high-index facets. J. Am. Chem. Soc. 132, 14012-14014 (2010)

35. Wang, F. et al. Heteroepitaxial growth of high-index-faceted palladium nanoshells and their catalytic performance. J. Am. Chem. Soc. 133, 1106-1111 (2011).

36. Zhang, L., Niu, W. \& Xu, G. Synthesis and applications of noble metal nanocrystals with high-energy facets. Nano Today 7, 586-605 (2012).

37. Quan, Z., Wang, Y. \& Fang, J. High-index faceted noble metal nanocrystals. Acc. Chem. Res. 46, 191-202 (2013).

38. Sun, Y. et al. Ambient-stable tetragonal phase in silver nanostructures. Nat. Commun. 3, 971-976 (2012).

39. Yacamán, M. J., Ascencio, J. A., Liu, H. B. \& Gardea-Torresdey, J. Structure shape and stability of nanometric sized particles. J. Vac. Sci. Technol. B 19, 1091-1103 (2001).

40. Ma, Y. et al. Seed-mediated synthesis of truncated gold decahedrons with a $\mathrm{AuCl} /$ oleylamine complex as precursor. Adv. Mater. 22, 1930-1934 (2010).

41. Elechiguerra, J. L., Reyes-Gasgab, J. \& Yacamán, M. J. The role of twinning in shape evolution of anisotropic noble metal nanostructures. J. Mater. Chem. 16, 3906-3919 (2006).

42. Mayoral, A., Barron, H., Estrada-Salas, R., Vazquez-Duran, A. \& Yacamán, M. J. Nanoparticle stability from the nano to the meso interval. Nanoscale 2, 335-342 (2009)

43. Personick, M. L., Langille, M. R., Zhang, J. \& Mirkin, C. A. Shape contro of gold nanoparticles by silver underpotential deposition. Nano Lett. 11, 3394-3398 (2011).

44. Liu, D., Mori, A. \& Huang, L. Role of liposome size and RES blockade in controlling biodistribution and tumor uptake of GM1-containing liposomes. Biochim. Biophys. Acta 1104, 95-101 (1992).

45. Bagley, A. F., Hill, S., Rogers, G. S. \& Bhatia, S. N. Plasmonic photothermal heating of intraperitoneal tumors through the use of an implanted nearinfrared source. ACS Nano 7, 8089-8097 (2013).

46. Schrinner, M. et al. Single nanocrystals of platinum prepared by partial dissolution of Au-Pt nanoalloys. Science 323, 617-620 (2009).

47. Zeng, J., Zhang, Q., Chen, J. \& Xia, Y. A comparison study of the catalytic properties of Au-based nanocages, nanoboxes, and nanoparticles. Nano Lett. 10, 30-35 (2010).

48. Yu, T., Zeng, J., Lim, B. \& Xia, Y. Aqueous-phase synthesis of $\mathrm{Pt} / \mathrm{CeO}_{2}$ hybrid nanostructures and their catalytic properties. Adv. Mater. 22, 5188-5192 (2010).

49. Praharaj, S., Nath, S., Ghosh, S. K., Kundu, S. \& Pal, T. Immobilization and recovery of $\mathrm{Au}$ nanoparticles from anion exchange resin: resin-bound nanoparticle matrix as a catalyst for the reduction of 4-nitrophenol. Langmuir 20, 9889-9892 (2004).

\section{Acknowledgements}

This work was supported by MOST of China (2011CB921403, 2014CB932700 and 2013CB733802), NSFC under Grant Nos 21121003, 21203173, 51273165, 51371164, 81101101, 81371596 and J1030412, Strategic Priority Research Program B of the CAS under Grant No. XDB01020000, Program for New Century Excellent Talents in University (NCET-13-0502), and Fundamental Research Funds for the Central Universities (WK2340000050, WK2060190025 and 2013121039). 


\section{Author contributions}

R.H., Y.-C.W. and Xiaoy.W. equally made the most important contributions, although all authors made contributions to the work. R.H., Y.-C.W., X.C. and J.Z. designed the studies and wrote the paper. R.H. and Y.-C.W. performed most of the experiments. W.Z. and L.W. obtained results in Fig. 4b. Xiaoy.W., Z.W. and G.L. performed photothermal therapy and related data analysis. Q.L., Xiaop.W. and J.G.H. commented on the manuscript.

\section{Additional information}

Supplementary Information accompanies this paper at http://www.nature.com/ naturecommunications

Competing financial interests: The authors declare no competing financial interests.
Reprints and permission information is available online at http://npg.nature.com/ reprintsandpermissions/

How to cite this article: He, R. et al. Facile synthesis of pentacle gold-copper alloy nanocrystals and their plasmonic and catalytic properties. Nat. Commun. 5:4327 doi: $10.1038 /$ ncomms5327 (2014).

(c) (i) (2) This work is licensed under a Creative Commons AttributionNonCommercial-ShareAlike 4.0 International License. The images or other third party material in this article are included in the article's Creative Commons license, unless indicated otherwise in the credit line; if the material is not included under the Creative Commons license, users will need to obtain permission from the license holder to reproduce the material. To view a copy of this license, visit http:// creativecommons.org/licenses/by-nc-sa/4.0/ 